\title{
A Study of Human Leukocyte D Locus Related Antigens in
}

\section{Graves’ Disease}

\author{
Nadir R. Farid, laura Sampson, Elke P. Noel, John M. Barnard, \\ Robert Mandeville, Bodil LarSen, and William H. Marshall, Faculty of \\ Medicine, Memorial University of Newfoundland, St. John's, Newfoundland, \\ Canada A1B 3V6 \\ NiCHOLAS D. CARTER, St. Georges Hospital, Blackshaw Road, London SW17, England
}

\begin{abstract}
A B S T RACT An association between Graves' disease and the human leukocyte antigen (HLA) system has previously been reported. The disease was more strongly associated with the HLA D locus antigen Dw3 than with HLA B8. Products of the HLA D locus are determined by the interaction of test cells with standard typing lymphocytes, a technically difficult procedure. Recently, it has been possible to type serologically for D locus related (DRw) specificities on peripheral bone marrow-derived (B) lymphocytes. Blood B lymphocytes from 50 unrelated controls and 41 patients with Graves' disease were typed for seven HLA DRw specificities. 28 patients with Graves' disease $(68 \%)$ were positive for DRw3, in contrast to 14 controls (28\%); whereas only 21 patients $(50 \%)$ were HLA B8 positive, compared with $13(26 \%)$ controls. Thus, positivity for DRw3 afforded a relative risk for Graves' disease of 5.5, whereas that for HLA B8 amounted to 3.0. Additionally, a family with multiple cases of Graves' disease in which the disease was previously shown to be inherited with the haplotype, was linked to DRw2, which suggests that the susceptibility to the disease was inherited in association with that antigen. Two HLA B/glyoxalase recombination events were observed in this family; in both instances HLA DRw followed HLA B. This study thus demonstrates that the disease susceptibility gene for Graves' disease is in strong linkage disequilibrium with DRw3; however, it may be associated with other DRw specificities and inherited within family units in association with them.
\end{abstract}

\section{INTRODUCTION}

The human leukocyte antigen (HLA) ${ }^{1}$ complex is determined by a number of genes, several of which have

\footnotetext{
This work was presented in part at the 60th Annual Meeting of the Endocrine Society, Miami Beach, Fla., June 1978.

Received for publication 6 March 1978 and in revised form 14 August 1978.

${ }^{1}$ Abbreviations used in this paper: B lymphocytes, bone marrow-derived lymphocytes; Bf, properdin-rich factor B;
}

been identified and individually designated (HLA A, $B, C$, and D). The first three are serologically detected; the D gene codes for the expression of products detected in the mixed lymphocyte culture reaction. Many other genes are known to be located near or in the HLA complex (1).

In mice, genetic mapping has shown that genes which control the immune response are located between those of the $\mathrm{D}$ and $\mathrm{K}$ determinants of the major histocompatibility complex (2), and may not be separable from those coding for Ia surface antigens (3). The I-region associated (Ia) antigens appear to determine the intensity of the mixed lymphocyte culture reaction (4), and are probably analogous with the lymphocytedefined antigens of man (5).

Although the precise relationship of I-region associated (Ia) antigens to immune response (Ir) gene effects is not known, there is considerable reason to believe that Ir gene products are expressed on thymus-dependent $(T)$ cells $(6,7)$. There is, however, evidence which indicates that Ir gene effects may also be functionally expressed on bone marrow-derived (B) lymphocytes (8). Ia antigens have been identified as components of antigen-specific helper factors (8), antigen-specific suppressor factors (9), and antigen-nonspecific "allogeneic effect" factors (10). They are also involved in the mediation of immunoglobulin $(\mathrm{Ig}) \mathrm{M} /$ IgG switch in the course of the humoral immune response (11).

In recent years, a large number of human diseases have been found to be associated with certain HLA

Glo, red cell glyoxalase I; HLA, the first (A) human leukocyte antigen discovered, (the term is now used to cover a genetic system composed of four loci identified as A, B, C, and D); HLA DRw, HLA D locus related antigens; I, part of the mouse histocompatibility complex between the $K$ and $D$ regions and nearer $K$; Ia, or I-region associated antigens are controlled by genes in this region; Ir, or immune response genes map in the I region and control the capacity to respond to certain antigens; $T$ lymphocytes, thymus-dependent lymphocytes. 
antigens (12). These disease associations may be broadly divided into those in which the primary association is with D locus alleles, and those whose associations are stronger with the $\mathrm{A}, \mathrm{B}$, or $\mathrm{C}$ alleles; diseases that belong to the first category have in common an autoimmune basis. In analogy with the mouse histocompatibility complex, it is not unreasonable to suspect that the disease susceptibility genes in those instances would be identical to the $D$ locus or map in the vicinity of that locus. The realization that certain human pregnancy sera could block stimulation (by B cells) in the mixed lymphocyte culture reaction raised hopes which were subsequently justified that the polymorphisms of D locus related specificities (DRw) may be serologically identified (13).

In this report, we describe the development of local reagents capable of typing HLA DRw specificities and the use of these sera to define DRw antigens among unrelated patients suffering from Graves' disease. We have also examined inheritance of these specificities along with products of HLA A, B, and C loci in a family with multiple cases of Graves' disease.

\section{METHODS}

The sera. 740 pregnancy sera were studied, after absorption with platelets pooled from 50 different donors. The sera were screened for the presence of $B$ lymphocytotoxic antibodies against a panel of 113 persons with a wide variety of HLA phenotypes. 90 sera $(12 \%)$ were found to react against one or more of the lymphocytes of the 113 individuals tested. These sera were specifically cytotoxic for B cells, in that when tested against the same individual's $T$ lymphocytes no parallel pattern of reactivity was observed.

The employing of $2 \times 2$ chi-square analysis of the serum reactions and comparing each serum in turn with every other serum (14) led to the definition of 45 clusters.

Specificity. The specificities of the sera which define each of the $\mathbf{4 5}$ clusters were established in three ways. Firstly, we retyped 14 individuals who were assigned DRw specificities during the Seventh International Histocompatibility Testing Workshop. Secondly, we included in the panel a number of individuals previously typed for the $\mathrm{D}$ locus by homozygous cell typing (Courtesy of $\mathrm{E}$. Thorsby); the following antigens were identified: Dw2, Dw3, Dw6, and Dw7. Thirdly, we parallel-typed a panel of 49 donors with 12 sera of known DRw specificity (courtesy of Dr. D. B. Hare, of the National Institutes of Health). It was thus possible to assign DRw specificities to 35 of the 45 serum cluster groups which defined the DRw antigens $1-7$.

The specificity DRw3 was defined by 13 specific sera, as well as by 12 multispecific and 'broad sera'. The following Seventh International Histocompatibility sera specific for HLA DRw3 were studied in parallel with the local sera: AH 315 (E. Thorsby); McCooga (H. Dick); MO 19392 (J. J. van Rood); P98411 (A. Tilikainen); and B15 IRV (P. I. Terasaki). Serum AH 315 was found to show the highest degree of association in the Workshop cluster, corresponding to DRw3 as well as with HLA Dw3. Eight of our specific sera had $r$ values of 0.48 or greater (maximum of 0.74 ) in relation to this serum ( $r=\sqrt{\chi^{2} / n}$, where $n$ is the number of lymphocyte donors tested). The other four VII Workshop sera are strongly correlated with $\mathrm{AH} 315$ as well as with each other.

Two National Institutes of Health sera (Held and Wankowski, donated by Dr. Rodey, Milwaukee, Wis.) with
DRw3 activity were used to establish the specificity of clusters which contained the 13 DRw3 sera.

Lyophilized rabbit serum as source of complement was purchased from Cedarlane Laboratories Ltd., London, Ontario, Canada.

Subjects. We studied 41 sequential unrelated patients suffering from Graves' disease and 50 controls with no personal or family history of thyroid disease and normal thyroid function tests. All patients and controls were adult Caucasians drawn from the Avalon Peninsula of Newfoundland. Graves' disease was diagnosed on the basis of clinical features, thyroidal radioiodine uptake and rectilinear scanning, and elevated serum thyroid hormone levels. These 91 individuals together with a further 40 people were coded and their DRw specificities determined 'blind' (without knowledge of their identity or their HLA phenotypes). We also restudied a previously reported (15) sibship with multiple cases of Graves' disease. It was now possible to 'split' some of the A and B locus antigens and type for the $C$ locus as well as for DRw specificities. Two members of this sibship were found to be HLA B/glyoxalase recombinants (previously unreported). It was thus possible to examine the segregation of $\mathrm{DRw}$ region within this family.

Leukocyte separation. Lymphocytes separated from $50 \mathrm{ml}$ of heparinized blood were used to screen for useful DRw reagents. Subsequently, $20 \mathrm{ml}$ were used for HLA DRw typing. Leukocytes were separated by Ficoll-Hypaque (Pharmacia Fine Chemicals Inc., Piscataway, N. J.) gradient centrifugation (16) and adjusted to $4 \times 10^{6} / \mathrm{ml}$. Equal $(0.5 \mathrm{ml})$ volumes of lymphocytes and of $1 \%$ sheep erythrocytes (Connaught Medical Research Laboratory, Willowdale, Ontario, Canada) suspended in tissue culture Medium 199 (Grand Island Biological Co., Berkeley, Calif.) and $10 \%$ fetal calf serum (Grand Island Biological Co.) were mixed and incubated at $37^{\circ} \mathrm{C}$ for $15 \mathrm{~min}$, and subsequently held at $4^{\circ} \mathrm{C}$ overnight. The percentage of cells that formed rosettes was determined microscopically after gentle resuspension. The contents of several tubes were pooled, gently layered onto FicollHypaque gradients, and spun at $500 \mathrm{~g}$ for $30 \mathrm{~min}$ (17). The cells at the interface ( $B$ cells) were removed, washed, resuspended in medium, and adjusted to $2 \times 10^{6} / \mathrm{ml}$. The purity of the B-cell preparation was checked by immunofluorescence for surface immunoglobulins with fluorescein-conjugated rabbit anti-Ig serum (The Wellcome Foundation Ltd., The Wellcome Research Laboratories, Beckenham, Kent, England) and sheep erythrocyte rosettes for evidence of $\mathrm{T}$ cell contamination. On the average, $70 \%$ of the B-cell fraction was positive for surface immunoglobulins with $<10 \%$ contamination with T cells. $90 \%$ or greater of the B-cell fraction used for DRw typing were viable as defined by trypan blue exclusion.

HLA typing. All controls and patients were typed for $14 \mathrm{~A}$ locus antigens and $16 \mathrm{~B}$ locus antigens. In a number of patients and controls, as well as in members of the sibship reported, it was possible to split A9 into Aw23 and Aw24; A10 into Aw25, Aw26, and Aw34; Bw16 into Bw38 and Bw39; and to further identify Aw32 and $A w 33 ; B w 41, B w 42, B w 4$, and Bw6; and $\mathrm{Cw} 1$ to Cw5 (18). The typing sera panel was extended with the benefit of the Seventh International Histocompatibility sera.

The testing for HLA DRw was carried out with the 90 useful sera with a two-step complement-dependent microcytotoxicity assay (19).

Other methods. Allotypic variants of properdin-rich factor $B$ were determined by high voltage electrophoresis followed by immunoprecipitation (20) and those for glyoxalase (Glo) as described by Parr et al. (21).

Relative risk, and the statistical derivations therefrom were calculated as described by Svejgaard et al. (22). Chi-square tests were used to make comparisons. 


\section{RESULTS}

Reproducibility. 12 individuals were each typed on two occasions, separated by periods of several weeks, and DRw specificities assigned 'blind'. Excellent agreement was observed between serum reactions and DRw phenotypes (Table I). In only one of the 24 possible alleles was disagreement observed (4.1\%); instead of DRw1, the disparate allele was typed as a blank.

The number and identity of alleles. By assuming that one locus codes for DRw, it would be expected that two antigens would be detected in each individual. In many instances "extra" serum reactivities were observed. The majority of these reactions did not segregate with any of the seven DRw specificities although they segregated with HLA in three small sibships studied. As no instances of intra-HLA recombination events were observed, it was not possible to determine whether we were looking at the products of two loci, or whether these reactivities represented private antigens.

In three instances (two controls, and one patient with Graves' disease), the serum reactions clearly suggested the presence of three antigens (triplets). In each case, family information suggested that one of the 3 antigens was a result of 'extra' reactions (Table II). In 9 patients and 10 controls, only one DRw antigen could be detected by the reactant sera. B lymphocytes from one healthy control failed to react against any of the typing sera. Laboratory error was excluded by repeat testing;

TABLE I

Reproducibility of Serological Reactions and Antigen Assignments

\begin{tabular}{cccccccc}
\hline & \multicolumn{2}{c}{ Correspondence between two tests* } & & \multicolumn{2}{c}{ DRw phenotype } \\
\cline { 2 - 3 } \cline { 7 - 8 } No. & ++ & +- & -+ & -- & & First test & Second test \\
\hline 1 & 5 & 1 & 2 & 84 & & 2,4 & 2,4 \\
2 & 14 & 2 & 1 & 73 & & 1,3 & 1,3 \\
3 & 11 & 2 & 4 & 74 & & $3,-$ & $3,-$ \\
4 & 9 & 4 & 1 & 76 & & 3,6 & 3,6 \\
5 & 6 & 0 & 2 & 84 & & 1,7 & 1,7 \\
6 & 6 & 4 & 3 & 77 & & $3,-$ & $3,-$ \\
$7 \neq$ & 8 & 1 & 2 & 79 & & 4,6 & 4,6 \\
8 & 9 & 1 & 3 & 77 & & 3,4 & 3,4 \\
9 & 6 & 2 & 4 & 78 & & -7 & $1,7 *$ \\
10 & 9 & 2 & 1 & 78 & & 3,4 & 3,4 \\
11 & 5 & 2 & 2 & 81 & 4,5 & 4,5 \\
12 & 8 & 1 & 2 & 79 & 3,7 & 3,7 \\
\hline
\end{tabular}

Chi-square testing showed that highly significant agreement was found between the serum reactions in all individuals studied $\left(x^{2}>25\right)$.

* ++ signifies positivity for stated numbers of sera on both occasions; +- indicates positivity on first occasion but not on second and vice versa for -+ .

$\$$ Disagreement between two phenotype results.
TABLE II

The HLA A, B, C, and DRw Phenotypes among the 41 Patients with Graves' Disease Studied

\begin{tabular}{|c|c|c|c|c|}
\hline \multirow{2}{*}{$\begin{array}{c}\text { Patient } \\
\text { No. }\end{array}$} & \multicolumn{4}{|c|}{ HLA } \\
\hline & $\mathbf{A}$ & B & C & DRw \\
\hline 1 & 1,2 & $8,-$ & - & 3,7 \\
\hline 2 & $2, w 30$ & 5,13 & ND & 5,7 \\
\hline 3 & 2,28 & $12, \mathrm{w} 15$ & ND & 7, \\
\hline 4 & 1,11 & w35, & ND & 4, \\
\hline 5 & 2,3 & $12,-$ & Cw5 & 1,7 \\
\hline 6 & $2, w 29$ & $12, \mathrm{w} 22, \mathrm{w} 4, \mathrm{w} 6$ & Cw3 & 2,4 \\
\hline 7 & 9,10 & $8, w 21$ & ND & 3, \\
\hline 8 & 1,2 & 8, & ND & 3,4 \\
\hline 9 & 3,9 & $7, w 35$ & ND & 2,4 \\
\hline 10 & 11,11 & 18,27 & ND & $3,,_{-}^{*}$ \\
\hline 11 & 1,2 & 5,8 & ND & 1,3 \\
\hline 12 & 2,9 & 12,17 & ND & 3,4 \\
\hline 13 & 24,11 & 12, w35 & Cw4,Cw5 & 7, \\
\hline 14 & 3,10 & 7,8 & ND & 2,3 \\
\hline 15 & 1,2 & 8,14 & ND & 3, \\
\hline 16 & 2,10 & 12,18 & ND & 3, \\
\hline 17 & 1,3 & 8,18 & ND & 2,3 \\
\hline 18 & 3,7 & w40, & ND & 1,4 \\
\hline 19 & 3,10 & $8, w 35$ & ND & 1, \\
\hline 20 & 1,10 & 8,12 & ND & 3,7 \\
\hline 21 & 2, & w40,-,w6 & Cw2 Cw3 & 4,6 \\
\hline 22 & 1,2 & 8,12 & ND & 3,4 \\
\hline 23 & 3, & $18, w 15$ & Cw3 & 4,6 \\
\hline 24 & 1,28 & $8, w 40$ & ND & 3,7 \\
\hline 25 & 2, & 7,12 & ND & 2,7 \\
\hline 26 & 1,3 & $8, w 35$ & ND & 1,2 \\
\hline 27 & 1, & $8,-, w 6$ & - & 3,7 \\
\hline 28 & 1,3 & $8,-, w 6$ & - & 3,4 \\
\hline 29 & 9,10 & 8,12 & ND & 3,4 \\
\hline 30 & 3, & 7,14 & - & 3,4 \\
\hline 31 & 2, & $12, w 35$ & ND & 3, \\
\hline 32 & 2, & $8,-, w 6$ & - & $3,-*$ \\
\hline 33 & 1,3 & 7,8 & ND & 2,3 \\
\hline 34 & 2,9 & Bw40, & ND & 3,5 \\
\hline 35 & 1,2 & 8,17 & ND & 3,7 \\
\hline 36 & 3,10 & 12, & ND & 4, \\
\hline 37 & 2, & 7,8 & ND & 2,3 \\
\hline 38 & 1,2 & 7,8 & ND & $3,4(6) \neq$ \\
\hline 39 & 2,9 & 12,18 & ND & 3,5 \\
\hline 40 & 2,9 & $5, \mathrm{w} 22$ & ND & 2,3 \\
\hline 41 & 1, & $8, w 37$ & ND & 3, \\
\hline
\end{tabular}

$\mathrm{ND}$, Not done.

-, Tested but not detected.

* Both found to be homozygous DRw3 by family studies.

$\ddagger$ Three antigens were detected on the basis of serological reactions. In the control group, two individuals of phenotypes $1,7(5)$ and 2,3(4) were detected. Family studies in these three persons excluded the presence of the specificity in bracket.

the same individual also yielded similar results with VII Workshop typing sera (Table II).

$H L A$ results. HLA B8 was the only antigen for which significant deviations were observed in the 
Graves' disease group compared with controls (Table II). 21 out of 41 patients with Graves' disease were HLA B8, compared with 13 out of 50 controls. Thus, positivity for HLA B8 conferred a relative risk for Graves' disease of 2.99 (95\% confidence limits: 1.247.21) (22). This result was significant at the $2.5 \%$ level $\left(\chi_{1}^{2}=5.944\right)$. The rate of presumed HLA B8 homozygosity was observed (Table II) to be increased among the patients who suffered from Graves' disease (5 or $12.5 \%$ ) compared with control subjects ( 2 or $4 \%$ ). The difference between the patients and control in this series was, however, not significant $\left(\chi^{2}=2.2, P>0.1\right)$.

Table III shows that HLA DRw3 was the only antigen observed to be significantly increased among the Graves' disease group. Positivity for DRw3 resulted in a relative risk for Graves' disease of 5.4. In contrast to the increase of HLA B8 homozygosity among the Graves' disease group, homozygosity for DRw3 was observed in two patients compared with none in control subjects. In both patients, homozygosity for DRw3 was confirmed by family studies.

No correlation was found between HLA DRw3 positivity and goiter size, presence of ophthalmopathy, or thyroid autoantibody titres.

Family data. Fig. 1 depicts the sibship that contained four members who had suffered from Graves' disease (15). The disease susceptibility entered this family with the maternal haplotype HLA A24, Bw39, $\mathrm{Bw6}, \mathrm{Cw}_{-}$, and DRw2. Three out of four children to whom this haplotype was transmitted suffered from Graves' disease. It is of interest to note that despite the historical evidence that the two parents were unrelated, they were completely identical at one haplotype (A24, Bw39, Bw6, Cw_, DRw2, properdin-rich factor $[\mathrm{Bf}]$, and $\left.\mathrm{Glo}^{2}\right)$. Bf data was uninformative.

In two offspring, in whom recombination between HLA B and Glo was found, DRw was observed to follow the $B$ locus.

\section{DISCUSSION}

In a discussion of HLA-DRw antigens and the relevance of their associations with disease, two issues arise: (a) the relationship of HLA DRw to previously established HLA specificities and $(b)$ whether they are coded for by one or more loci. The Seventh Histocompatibility Workshop showed that the correspondence between HLA DRw serological results and HLA D typing were far from complete. Serologic testing of B cells resulted in broader specificities than those identified by HLA D homozygous cell typing, and narrower than their definition by cells previously sensitized to known HLA-D gene products (primed lymphocyte typing) (23). These findings can be interpreted as follows: either $(a)$ we are dealing with a complex molecule, and each of the three methods of typing look at different
TABLE III

The Frequency of HLA DRw Antigens Observed among Controls and Patients with Graves' Disease

\begin{tabular}{lrrrrrrrr}
\hline $\begin{array}{l}\text { HLA DRw antigens } \\
\begin{array}{l}\text { Graves' disease } \\
(n=41)\end{array}\end{array}$ & 1 & 2 & 3 & 4 & 5 & 6 & 7 & $*$ \\
$\quad$ Controls $(n=50)$ & 12 & 14 & 14 & 14 & 7 & 6 & 15 & 12
\end{tabular}

$x=5.54(95 \%$ confidence interval $2.24-13.65), \chi_{1}^{2}=13.83$, $P<0.0005 \quad(P<0.0035$ after correction for number of antigens tested).

* No antigen detected with sera used.

\$ HLA DRw3 is the only antigen with significant association.

parts of that complex; or $(b)$ the HLA D locus-region codes for several molecular species, each of which, or combinations of which, are identified by the different methods of typing. Concerning the question as to whether DRw specificities are coded for by one or more loci, recombinant family data suggested that $\mathrm{DRw}$ reagents may identify gene products of a second locus (24, 25) probably in the vicinity of HLA A (24). Additionally, comparison of primed lymphocyte and DRw typing suggested the presence of a locus mapping separate from DRw (26). At this stage of the art, and in the absence of family studies on intra-HLA recombinants, it is not possible to exclude the possibility that the additional specificities identified may represent private antigens that were not absorbed by platelets. This is, however, unlikely to be the explanation for the primed lymphocyte typed specificities. In our data we found examples of individuals whose B lymphocytes demonstrated extra reactions, which were heritable and segregated with HLA. In view of the high fre-

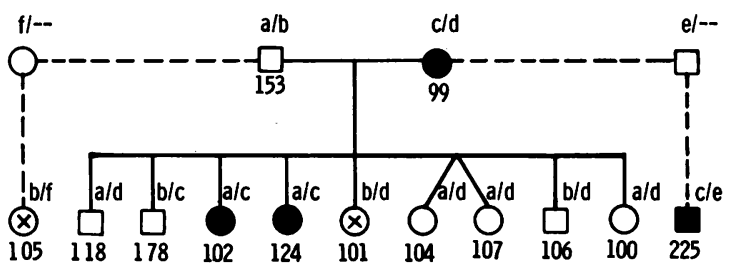

FIgure 1 The sibship studied $O=$ Females, $\square=$ Males, - Family members who had suffered from Graves' disease. $\mathrm{a}=\mathrm{A} 24, \mathrm{Bw} 39, \mathrm{Bw6}, \mathrm{Cw}$, DRw2, BfS, Glo²; b = Aw25, B12, Bw4, Cw5, DRw7, BfS, Glo ${ }^{1}$; $=\mathrm{A} 24, \mathrm{Bw} 39, \mathrm{Bw6}, \mathrm{Cw}$, DRw2, BfS, Glo²; d = A2, B17, Bw4, Cw6, DRw4, BfS, Glo²; $\mathrm{e}=\mathrm{A1}, \mathrm{B} 8, \mathrm{Bw6}, \mathrm{Cw}, \mathrm{DRw}, \mathrm{BfS}, \mathrm{Glo}^{2} ; \mathrm{f}=\mathrm{Aw} 32, \mathrm{B18}, \mathrm{Bw6}$, $\mathrm{Cw}_{\rightarrow}, \mathrm{DRw}_{-}, \mathrm{BfS}, \mathrm{Glo}^{2}$. (-----) signifies illegitimacy, first suspected on the basis of the HLA results, and later confirmed by typing for 23 polymorphisms. ( $x$ ) indicates cross-over between HLA $B$ and Glo loci on the $b$ haplotype in both No. 101 and 105. Although it is customary not to accept more than one recombinant in a sibship, we have retained the two HLA B/Glo recombinants observed (No. 105 and 101) in view of the reported distance between the two loci (three recombination units). 
quency of the extra reactions among the people studied, it was unlikely that these represented private antigens. As concerns the occurrence of apparent triplets, these were probably related to multispecificity of some sera.

Against this background, we have used specific reagents to type patients with Graves' disease for HLA DRw antigens. Our results showed that HLA DRw3 was increased among patients with Graves' disease and resulted in a stronger association than that conferred by HLA B8. It was previously known that HLA B8 and HLA Dw3, which show marked linkage disequilibrium (27), were increased among patients with Graves' disease compared with controls (28-31). A stronger association with Graves' disease was observed for HLA Dw3 than for B8. We reported earlier that apparent (in the absence of family data) homozygosity for HLA B8 increased the relative risk for Graves' disease several-fold over heterozygosity (29). Without typing for HLA-D (or HLA DRw) it was not possible to answer the question of whether the disease susceptibility gene was recessive or whether HLA B8 homozygote individuals were more likely to be HLA Dw3 positive than heterozygotes; family data (15) was more in keeping with a modified dominant mode of inheritance. We now find no increase of HLA DRw3 homozygosity over that expected. This finding along with the stronger association of Graves' disease with DRw3 suggests that the susceptibility to the disease is inherited as a dominant character (15). Such a mode of inheritance is in agreement with what has been described for Ir genes in the murine system. While the presence of thyroid-stimulating antibody, known to be causally related to Graves' disease, did not appear to be associated with HLA B8 positivity (32), it was shown that the disease in HLA Dw3 (and HLA B8) positive individuals was less likely to remit after antithyroid drug therapy compared with Dw3 negative patients, which suggests persistance of thyroid-stimulating antibody in the former $(31,33)$. This interesting possibility, however, needs to be substantiated by formal thyroid-stimulating antibody assays.

In the family included in this study, Graves' disease was associated with the maternal haplotype HLA A24, Bw39, Cw_, DRw2, BfS, and Glo2. This haplotype was passed on to four offspring, three of whom went on to develop Graves' disease. This family does not provide evidence for the inheritance of the susceptibility to Graves' disease in association with the DRw locus rather than the $\mathrm{A}, \mathrm{B}$, or $\mathrm{C}$ (31) loci. However, the fact that we have demonstrated that the susceptibility was more closely associated with HLA DRw3 is more in keeping with such an assumption. The association and inheritance of DRw2 with Graves' disease is direct evidence that the association with Bw39 was not a result of a chance linkage of that antigen with DRw3. This finding also stresses the fact that Graves' disease may be associated with DRw alleles other than DRw3; and that once the linkage between the disease susceptibility gene with DRw2 is established, both are inherited closely together (with no evidence of recombination). It is clear that the disease susceptibility gene is not identical with HLA DRw3, but is in linkage disequilibrium with it. It is also randomly associated with other HLA DRw alleles.

The two Glo/HLA recombinants observed in this family show that the DRw follows the HLA B locus, which suggests that the chromosomal break occurred outside the $\mathrm{D}$ region.

In conclusion, typing for HLA DRw specificities showed that only two-thirds of patients with Graves' disease were positive for HLA DRw3. Further work is clearly indicated to pursue stronger associations with the disease. Refinement of serological typing for the equivalent of the apparently heterogeneous HLA Dw3 (34) as well as typing for products of other loci in the HLA region are two such approaches.

\section{ACKNOWLEDGMENTS}

We wish to thank Dr. David Bryant for assistance with data reduction, Mr. Terry Lomax of the Memorial University Computer Laboratory for data processing, Dr. John Bear for genetical advice, and Miss Roxanne Butler for secretarial assistance.

This work was supported in part by grants from the Medical Research Council of Canada, the National FoundationMarch of Dimes, and the Faculty of Medicine Research Fund.

\section{REFERENCES}

1. Svejgaard, A., M. Mauge, C. Jersild, P. Platz, L. P. Ryder, L. Staub Nielson, and M. Thomsen. 1975. The HLA system: an introductory survey. Monogr. Hum. Genet. 7: 3102.

2. McDevitt, H. O., B. D. Deak, D. C. Shreffler, J. Klein, J. H. Stimpfling, and G. D. Snell. 1972. Genetic control of the immune response, mapping of 1r-1 locus. J. Exp. Med. 135: 1259-1278.

3. Cullen, S. E., C. S. David, J. L. Cone, and D. H. Sachs. 1976. Evidence for more than one Ia antigenic specificity on molecules determined by the I-A subregion of the mouse major histocompatibility complex. J. Immunol. 116: 549-553.

4. Lozner, E. C., D. H. Sachs, G. M. Shearer, and W. D. Terry. 1974. B cell alloantigens determined by the H-2 linked $1 \mathrm{r}$ region are associated with mixed lymphocyte culture stimulation. Science (Wash. D. C.). 183: 757-759.

5. Bach, F. H., M. B. Widmer, M. L. Bach, and J. Klein. 1972. Serologically defined and lymphocyte-defined components of the major histocompatibility complex in the mouse. J. Exp. Med. 136: 1430-1444.

6. Benacerraf, B., and H. O. McDevitt. 1972. Histocompatibility-linked immune response genes. Science (Wash. D. C.). 175: 273-279.

7. Bechtol, K. B., and H. O. McDevitt. 1976. Antibody response of $\mathrm{C} 3 \mathrm{H}-(\mathrm{CKBXCWB}) \mathrm{F}_{1}$ tetraparental mice to (T,G) . . . A . . . L immunization. J. Exp. Med. 144: $123-144$

8. Taussig, M. J., A. J. Munro, R. Campbell, C. S. David, 
and N. A. Staines. 1975. Antigen-specific T-cell factor in cell cooperation, mapping within the I region of $\mathrm{H}-2 \mathrm{Com}-$ plex and ability to cooperate across allogeneic barriers. J. Exp. Med. 142: 694-700.

9. Tada, T., and M. Taniguchi, 1976. Characterization of the antigen-specific suppressive $T$ cell factor with special reference to the expression of I region genes. In The Role of the Products of the Histocompatibility Gene Complex in Immune Responses. D. H. Katz and B. Benacerraf, editors. Academic Press, Inc., New York. 513-534.

10. Armarding, D., and D. H. Katz. 1974. Activation of T and B lymphocytes in vitro. II. Biological and biochemical properties of an allogeneic effect factor (AEF) active in triggering specific B lymphocytes. J. Exp. Med. 140: 1937.

11. McDevitt, H. O., T. L. Delovitch, J. L. Press, and D. B. Murphy. 1976. Genetic and functional analysis of the Ia antigens. Their possible role in regulating the immune response. Transplant. Rev. 30: 197-235.

12. Sasazuki, T., H. O. McDevitt, and F. C. Grumet. 1977. The association between genes in the major histocompatibility complex and disease susceptibility. Ann. Rev. Med. 28: 425-452.

13. Van Rood, J. J., A. van Leeuwen, A. Termijtelen, and J. J. Keuning. 1976. The genetics of major histocompatibility complex in man, HLA. In The Role of Products of the Histocompatibility Gene Complex in Immune Responses. D. H. Katz and B. Benacerraf, editors. Academic Press, Inc., New York. 31-49.

14. Bodmer, W. F., J. G. Bodmer, D. Ihdhe, and S. Adler. 1969. Genetic and serological association analysis of the HLA leucocyte system. In Computer Applications in Genetics. N. E. Morton, editor. University of Hawaii Press, Honolulu, Hawaii. 117-127.

15. Farid, N. R., J. M. Barnard, W. H. Marshall, I. Woolfrey, and R. F. O'Driscoll. 1977. Thyroid autoimmune disease in a large Newfoundland family: the influence of HLA. J. Clin. Endocrinol. Metab. 45: 1165-1172.

16. Böyum, A. 1968. Isolation of leucocytes from human blood. Scand. J. Clin. Lab. Invest. 21(Suppl. 97): 9-29.

17. Aiuti, F., J-C. Cerottini, R. R. A. Coombs, M. Cooper, H. B. Dickler, S. S. Frøland, H. H. Fudenberg, M. F. Greaves, H. M. Grey, H. G. Kunkel, J. B. Natvig, J-L. Preud'homme, E. Rabellino, R. E. Ritts, D. S. Rowe, M. Seligmann, F. P. Seigel, J. Stjernswärd, W. D. Terry, and J. Wybran. 1974. Identification, enumeration and isolation of $\mathrm{B}$ and $\mathrm{T}$ lymphocytes from human peripheral blood. Scand. J. Immunol. 3: 521-532.

18. Mittal, K. K., M. R. Mickey, D. P. Singal, and P. I. Terasaki. 1968. Sero-typing for homotransplantation XVIII Refinement of microdroplet lymphocyte cytotoxicity test. Transplantation. 6: 913-927.

19. Bodmer, J., P. Pickbourne, W. Bodmer, R. Batchelor, P. Dewar, H. Dick, C. Entwistle, H. Festenstein, K. Gelsthorpe, V. Joysey, P. MacKintosh, S. Lawler, P. Morris, G. D. Pergrum, R. Harris, and M. Taylor. 1976. Serological identification of Ia Antigens: report of a British Region Ia Workshop. Tissue Antigens. 8: 359-371.

20. Larsen, B., A. Armason, J. M. Barnard, S. K. Buehler, J. H.
Edwards, and W. H. Marshall. 1977. Bf types of HLA haplotyped individuals in an isolated Newfoundland population. Tissue Antigens. 10: 309-316.

21. Parr, C. W., I. A. Bagister, and S. G. Walsh. 1977. Human red cell glyoxylase I polymorphism. Biochem. Genet. 15: $109-113$.

22. Svejgaard, A., C. Jersild, L. Staub Nielsen, and W. F Bodmer. 1974. HL-A antigens and disease. Statistical and genetical consideration. Tissue Antigens. 4: 95-105.

23. Histocompatibility Testing. 1977. W. F. Bodmer, J. R. Batchelor, J. G. Bodmer, H. Festenstein, P. J. Morris, editors. Munksgaard, Copenhagen.

24. Mann, D. L., L. Abelson, S. Harris, and D. B. Amos. 1976. Second genetic locus in the HLA region for human B cell alloantigens. Nature (Lond.). 259: 145-146.

25. Van Rood, J. J., A. van Leeuwen, J. J. Keuning, and A. Termijtelen. 1977. Evidence for two series of B-cell antigens in man and their comparison with HLA-D. Scand. J. Immunol. 6: 373-384.

26. Sasportes, M., D. Fradelizi, A. Nunez-Roldan, Z. Giannopolus, and J. Dausset. 1977. Preponderant role of $\mathrm{Li}$-Ly determinants as stimulating products in secondary allogenic proliferative response in man. Tissue Antigens. 10: 162. (Ábstr.)

27. Thorsby, E., and A. Piazza. Joint report from the Sixth International Histocompatibility Workshop Conference II. Typing for HLA-D (LD-1 or MLC) determinants. In Histocompatibility Testing. 1975. F. Kissmeyer-Nielsen, editor. Munksgaard, Copenhagen. 414-458.

28. Grumet, F. C., R. O. Payne, J. Konishi, and J. P. Kriss. 1974. HLA antigens as markers for disease susceptibility and autoimmunity in Graves' disease.J. Clin. Endocrinol. Metab. 39: 1115-1119.

29. Farid, N. R., J. M. Barnard, and W. H. Marshall. 1976. The association of HLA with autoimmune thyroid disease in Newfoundland. The influence of HLA homozygosity in Graves' disease. Tissue Antigens. 8: 181-189.

30. Thorsby, E., E. Segaard, J. M. Solem, and L. Kornstad. 1975. The frequency of major histocompatibility antigens (SD \& LD) in thyrotoxicosis. Tissue Antigens. 6: 54-55.

31. Bech, K., B. Lumholtz, J. Nerup, M. Thomsen, P. Platz, L. Ryder, A. Svejgaard, K. Siersback-Nielsen, J. Mølholm Hansen, and J. Larsen. 1977. HLA antigens in Graves' disease. Acta Endocrinol. 86: 510-516.

32. Wenzel, K. W., W. Weize, H. P. Kotulla, H. Scheusmer, and F. Adlkofer. 1976. Different association of histocompatibility antigens (H. A.) in patients with Graves' disease (G. D.) or autonomous adenoma (AA) and its correlation to human thyroid stimulating globulins (HSI). The 7th Annual Meeting of the European Thyroid Association, Helsinki, Finland.

33. Irvine, W. J., R. S. Gray, P. J. Morris, and A. Ting. 1977. Correlation of HLA and thyroid antibodies with clinical course of thyrotoxicosis treated with antithyroid drugs. Lancet. II: 898-900.

34. Van den Berg-Loomen, E. M., T. de Bruin, and P. T. A. Schellekens. 1977. The complex nature of human D-locus determinants: heterogeneity within DW3. Immunogenetics. 5: 261-270. 